\title{
ARTICLE
}

Received 30 Aug 2012 | Accepted 10 Oct 2012 | Published 13 Nov 2012

DOI: $10.1038 /$ ncomms2198

\section{Orthogonal switching of a single supramolecular complex}

Feng $\operatorname{Tian}^{1}$, Dezhi Jiao ${ }^{1}$, Frank Biedermann ${ }^{1} \&$ Oren A. Scherman ${ }^{1}$

Orthogonal control over systems represents an advantage over mono-functional switches as both the nature and order of distinctly different stimuli manifest themselves in a wide array of outcomes. Host-guest complexes with multiple, simultaneously bound guests offer unique opportunities to address a set of 'on' and 'off' states accessible on demand. Here we report cucurbit[8]uril-mediated host-guest heteroternary complexes constructed with both redoxand light-responsive guests in a single, supramolecular entity. The complex responds to orthogonal stimuli in a controlled, reversible manner generating a multifunctional switch between a 'closed' heteroternary complex, a redox-driven 'closed' homoternary complex and a photo-driven 'open' uncomplexed state. We exploit both photochemical and electrochemical control over the supramolecular coding system and its surface wettability to demonstrate the system's complexity, which could be readily visualized on a macroscopic level, thus offering new opportunities in the construction of memory devices.

\footnotetext{
${ }^{1}$ Melville Laboratory for Polymer Synthesis, Department of Chemistry, University of Cambridge, Lensfield Road, Cambridge CB2 1EW, UK. Correspondence and requests for materials should be addressed to O.A.S. (email: oas23@cam.ac.uk).
} 
$\mathrm{H}$ arnessing external control over a system in an aqueous environment and tuning its properties reversibly on demand has attracted considerable interest across the chemical and biological sciences ${ }^{1-4}$. The highly dynamic nature of supramolecular non-covalent processes offers versatile tools to utilize and amplify external stimuli in the manipulation of material properties through reversible stimuli-responsive molecular switching 5 . Recent efforts have been dedicated to gaining orthogonal control over supramolecular systems, whereby different responses can be triggered on demand with a specific order of input stimuli, representing versatility and complexity beyond unifunctional systems ${ }^{6}$. One attractive way to achieve this is to delicately combine host-guest molecular recognition with other non-covalent interactions, for example, metal-ligand or protein-ligand interactions ${ }^{7-10}$. A major limitation in the field, however, has been the incorporation of multiple responsive components into one single supramolecular entity directly. This would serve to overcome any incompatibility between two different types of non-covalent interactions, as well as increase the overall complexity of the system.

Among supramolecular stimuli-responsive systems, photosensitive host-guest complexes are of significant interest as light can be applied in a remote manner as an external stimulus and offers precise control over wavelength ${ }^{11}$. In particular, azobenzene derivatives have been extensively used as guests to form inclusion complexes with asymmetric macrocyclic hosts achieving binary photochemical devices ${ }^{12-17}$, based on its well-documented photoisomerism ${ }^{18}$. Although symmetric macrocyclic hosts such as cucurbit[n]urils, ( $n=7$ and 8 ) have been used to form either binary inclusion complexes with $\mathrm{CB}[7]^{19,20}$, or ternary complexes with $\mathrm{CB}[8]$ and methylviologen $\left(\mathrm{MV}^{2+}\right)^{21}$, no photoresponsive $\mathrm{CB}$ systems have been demonstrated. Although guests such as stilbene analogues ${ }^{22}$, naphthalene/anthracene derivatives ${ }^{23,24}$ and coumarins $^{25}$ have been used to form 2:1 homoternary complexes with $\mathrm{CB}[8]$, their irreversible photodimerizations limit further application in orthogonal switching.

As an alternative to photoresponsive systems, redox-responsive host-guest complexes represent another route for constructing supramolecular electromechanical devices ${ }^{26-28}$. Both ferrocene ${ }^{29}$ and viologen derivatives ${ }^{30,31}$ have been used as guests for supramolecular macrocyclic hosts ${ }^{32-37}$. In comparison with ferrocene derivatives, whose sizes only allow for the formation of 1:1 inclusion complexes with such hosts ${ }^{38}$, viologen derivatives have been widely used as guests in ternary complexes with $\mathrm{CB}[8]^{39-41}$. Although a variety of applications such as glucose sensing, peptide separation and selfassembly of dendrimers have been reported ${ }^{42-44}$, no previous report has demonstrated an orthogonal response with such a ternary system.

Herein, we report the design and construction of orthogonal stimuli-responsive single supramolecular entities based upon $\mathrm{CB}[8]$-mediated heteroternary complexation with viologen and azobenzene derivatives as functional guests in water (Fig. 1). As functionalization of the $\mathrm{CB}[8]$ macrocycle is not required for heteroternary complexation, the straightforward self-assembly process represents a versatile platform for the construction of orthogonal stimuli-responsive supramolecular systems. As both molecular guests experience distinct equilibria with the $\mathrm{CB}[8]$ host, reversible and orthogonal responses to discrete external stimuli were realised through both light-induced isomerization of azobenzene and redoxdriven dimerization of viologen. Furthermore, by surface modification, we demonstrate the amplification of orthogonal stimuli that can be readily visualized on a macroscopic level, and the potential to construct molecular devices with higher complexity.

\section{Results}

High selectivity of $\mathrm{MV}^{2+} \subset \mathrm{CB}[8]$ towards trans-azobenzene. To investigate the second binding event, a UV/visible (vis) titration was performed between an azobenzene derivative $\mathbf{1}$ and the preformed complex $\mathrm{MV}^{2}+\subset \mathrm{CB}[8]$. The relative decrease in absorbance of 1 (Fig. 2a, 320-500 nm) with a concomitant increase at $251 \mathrm{~nm}$ from $\mathrm{MV}^{2}+\subset \mathrm{CB}[8]$ generated an isosbestic point at $317 \mathrm{~nm}$, suggesting the heteroternary complex was indeed formed ${ }^{20}$. The significant quenching of the $n-\pi^{*}$ absorbance of $\mathbf{1}$ around $440 \mathrm{~nm}$ compared with the slight decrease of the $\pi-\pi^{*}$ absorbance at $363 \mathrm{~nm}$ suggests the relative abundance of trans-1 over its cis isomer counterpart upon the heteroternary complexation. One likely explanation is that cis-1 is geometrically unfavourable to be bound inside the cavity of $\mathrm{CB}[8]$ in the presence of $\mathrm{MV}^{2+}$ (Supplementary Fig. S1) ${ }^{21}$. Another possibility is that the higher polarity of cis-1 makes it more likely to remain solvated in an aqueous environment rather than be inside the hydrophobic cavity of $\mathrm{CB}[8]$. In contrast, when an aqueous solution of $\mathbf{1}$ was treated with $\mathrm{CB}[8]$, a dramatic colour change was observed from a yellow $\left(\lambda_{\max }=353 \mathrm{~nm}\right)$ to a dark-red $\left(\lambda_{\max }=502 \mathrm{~nm}\right)$ solution (Supplementary Fig. S2a). This unique colour change indicated the formation of an inclusion complex cis-1 $\subset \mathrm{CB}[8]$, which was confirmed by NMR (Supplementary Fig. S2b, isothermal titration calorimetry (ITC) was used to determine the binding constant of cis-1 towards $\mathrm{CB}$ [8], but it falls below the lower limit $\left(10^{3} \mathrm{M}^{-1}\right)$ of the measurement range $)^{20}$. It is clear from Fig. 2a that no specific cis-1-CB[8] interactions occurred in the heteroternary complex as no absorbance was observed at $502 \mathrm{~nm}$. Further confirmation was achieved by a displacement experiment whereby adding $\mathrm{MV}^{2+}$ into the preformed cis-1 $\subset \mathrm{CB}[8]$ displayed a disappearance of the characteristic colour of cis-1 $\subset \mathrm{CB}[8]$ as a consequence of breaking apart the cis-1 $\subset \mathrm{CB}[8]$ owing to the apparent difference of binding constants $\left(10^{5}-10^{6}\right.$ for $\mathrm{MV}^{2+}$, thus at least two orders of magnitude higher than that of cis-1 towards $\mathrm{CB}[8])$. The obvious colour difference between cis-1 $\subset \mathrm{CB}[8]$ (dark red) and $\left(\mathrm{MV}^{2+} \bullet\right.$ trans-1) $\subset \mathrm{CB}[8]$ (faint yellow) clearly suggested a different selectivity for $\mathrm{MV}^{2}+\subset \mathrm{CB}[8]$ and $\mathrm{CB}[8]$ alone as supramolecular hosts for different isomers of $\mathbf{1}$. Collectively the data suggest that $\mathrm{MV}^{2+} \subset \mathrm{CB}[8]$ selectively recognized the trans isomer as the better second guest over the cis isomer, leading to the formation of a 1:1:1 heteroternary complex $\left(\mathrm{MV}^{2+} \bullet\right.$ trans-1) $\subset \mathrm{CB}[8]$.

Formation of $\left(\mathrm{MV}^{2+} \bullet\right.$ trans-1) $\subset \mathrm{CB}[8]$ was further confirmed by both ${ }^{1} \mathrm{H}$ NMR spectroscopy and ESI-MS. Significant upfield shifts (Fig. 2biii) in the proton spectra of the aromatic region of both 1 and $\mathrm{MV}^{2+} \subset \mathrm{CB}[8]$ were observed compared to those of free 1 (Fig. 2bi) and $\mathrm{MV}^{2}+\subset \mathrm{CB}[8]$ (Fig. 2bii). This was likely on account of the shielding effect of the $\mathrm{CB}[8]$ cavity upon heteroternary complexation in $\mathrm{D}_{2} \mathrm{O}$. The $\mathrm{NMR}$ result was in good accordance with the mass spectrum, which showed a peak at $\mathrm{m} / z=865.04$ corresponding to a doubly charged heteroternary complex $[\mathrm{M}]^{2+}$ (Supplementary Fig. S3).

Photochemical switching upon light-driven isomerization. As 1 displayed relatively poor water solubility, it was decided to employ an asymmetric triethylene glycol modified azobenzene derivative $\mathbf{2}$ to facilitate ITC studies and thus gain a quantitative understanding of the difference in the binding affinity of $\mathrm{MV}^{2+} \subset \mathrm{CB}[8]$ towards the different isomers of azobenzene. As shown in Fig. 3a, when an aqueous solution of $\mathrm{MV}^{2+} \subset \mathrm{CB}[8]$ was titrated with trans-2, an isotherm was obtained suggesting a binding constant of $1.44 \pm 0.284 \times 10^{4} \mathrm{M}^{-1}\left(\mathrm{pH}=7\right.$ at $\left.25^{\circ} \mathrm{C}\right)$. In comparison, the binding constant between an immediately formed cis-2 (irradiated under UV light for $20 \mathrm{~min}$ ) and $\mathrm{MV}^{2+} \subset \mathrm{CB}$ [8] was too weak to be measured by ITC. The 
a

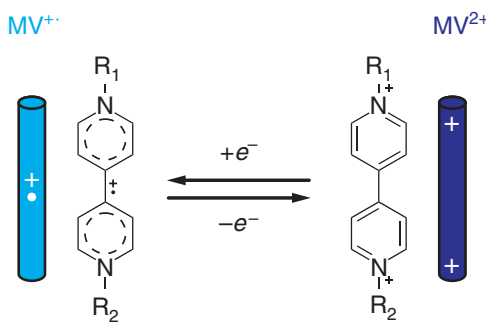

$\mathrm{MV}^{2+}$
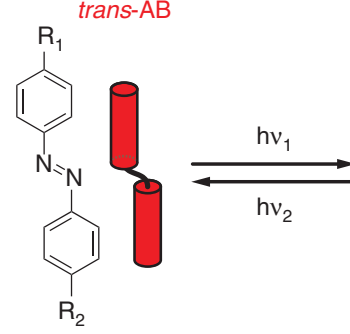

$$
\begin{aligned}
M V^{2+}: \mathrm{R}_{1} & =\mathrm{R}_{2}=\mathrm{CH}_{3} \\
M V^{2+} \mathrm{F}: \mathrm{R}_{1} & =\mathrm{CH}_{3} ; \\
\mathrm{R}_{1} & =\mathrm{C}_{2} \mathrm{H}_{4} \mathrm{NHC}(=\mathrm{S}) \mathrm{NHFluorescein}
\end{aligned}
$$

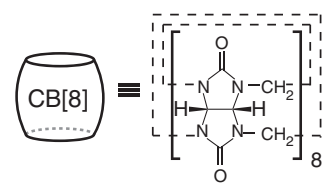

cis-AB

$\frac{1}{2} \mathrm{CB}[8] \quad \frac{1}{2}\left(\mathrm{MV}^{+}\right)_{2} \subset \mathrm{CB}[8]$

$\mathrm{MV}^{2+} \subset \mathrm{CB}[8]$

$\left(\mathrm{MV}^{2+} \cdot\right.$ trans-AB $) \subset \mathrm{CB}[8]$
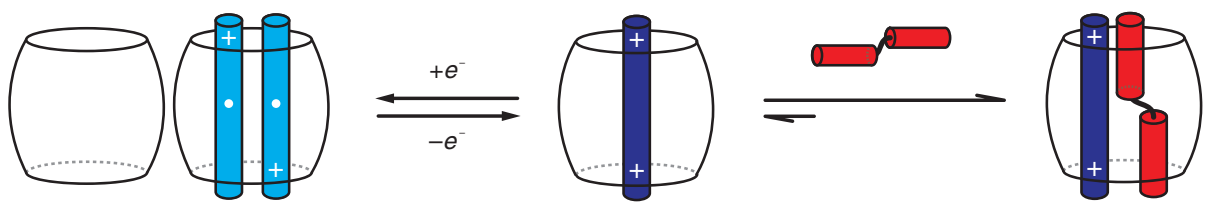

C $\left(\mathrm{MV}^{+}\right)_{2} \subset \mathrm{CB}[8]$ trans- $\mathrm{AB}$

$\left(\mathrm{MV}^{2+} \cdot\right.$ trans-AB $) \subset \mathrm{CB}[8]$

$$
\begin{aligned}
& \text { 1: } \mathrm{R}_{1}=\mathrm{R}_{2}=\mathrm{OH} \\
& \text { 2: } \mathrm{R}_{1}=\mathrm{H} ; \mathrm{R}_{2}=\left(\mathrm{OCH}_{2} \mathrm{CH}_{2}\right)_{3} \mathrm{H} \\
& \text { 3: } \mathrm{R}_{1}=\mathrm{H} ; \mathrm{R}_{2}=\mathrm{O}\left(\mathrm{CH}_{2}\right)_{11} \mathrm{SH}
\end{aligned}
$$
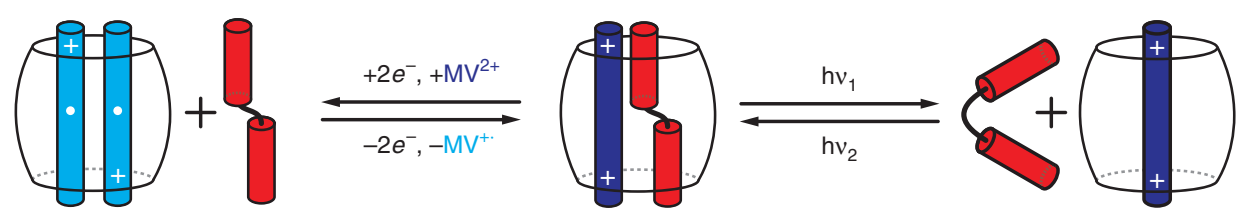

Figure 1 | Schematic illustration of the design, formation and orthogonal switching of a heteroternary complex. (a) Redox-induced reversible transition between $\mathrm{MV}^{2+}$ and $\mathrm{MV}^{+} \cdot$, and light-driven photoisomerization of azobenzene derivatives. (b) Stepwise formation of Cucurbit[8]uril (CB[8])-mediated heteroternary complex with $\mathrm{MV}^{2+}$ as the first guest and an azobenzene derivative as the second guest, as well as the one-electron reduction of $\mathrm{MV}^{2}+\subset \mathrm{CB}[8]$. (c) The redox-driven reversible transition between a 'close' heteroternary complex and a 'close' homoternary complex with the trans isomer, as well as the light-driven reversible transition between a 'close' heteroternary complex and an 'open' inclusion complex with the cis isomer.

a

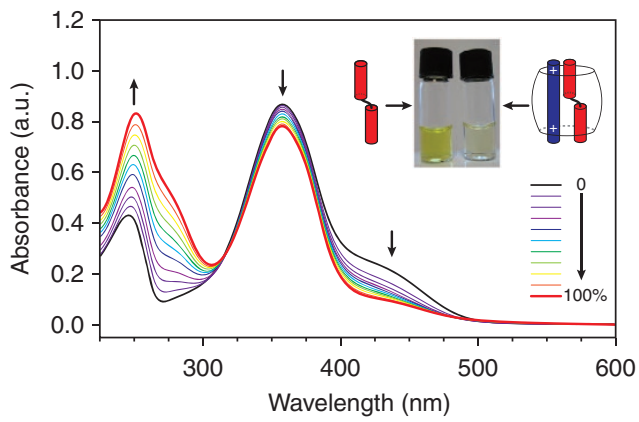

b iii

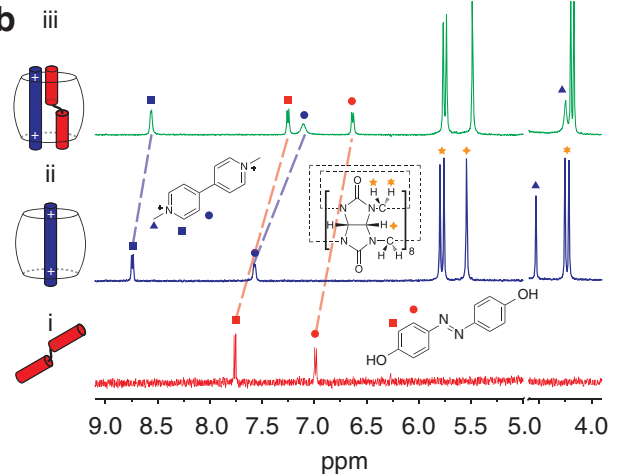

Figure 2 | Formation of heteroternary complex. (a) UV/vis titration of $\mathbf{1}$ upon increasing amount of $\mathrm{MV}^{2+} \subset \mathrm{CB}[8]$ (molar ratio from 0 to $100 \%$ ) in water at $\mathrm{pH}=7$ at $25^{\circ} \mathrm{C}$. A $0.05 \mathrm{mM}$ solution of $\mathbf{1}$ was kept in dark at $25^{\circ} \mathrm{C}$ overnight before starting the titration. Inset: solutions of $\mathbf{1}$ at $0.05 \mathrm{mM}$ in water at $\mathrm{pH}=7$ at $25^{\circ} \mathrm{C}$ (left) alone, (right) in the presence of an equimolar preformed 1:1 complex $\mathrm{MV}^{2}+\subset \mathrm{CB}[8](0.05 \mathrm{mM})$. (b) ${ }^{1} \mathrm{H} \mathrm{NMR}$ spectra of (i) $\mathbf{1}$, (ii) preformed complex $\mathrm{MV}^{2+} \subset \mathrm{CB}[8]$ and (iii) heteroternary complex $\left(\mathrm{MV}^{2+}\right.$ - trans-1) $\subset \mathrm{CB}[8]$ at $0.5 \mathrm{mM}$ in $\mathrm{D}_{2} \mathrm{O}$ at $\mathrm{pH}=7$ at $25^{\circ} \mathrm{C}$. The area around HOD peak between 4.6-5.0 ppm was removed for clarity.

combined UV/vis, NMR and ITC data all point to a substantially higher $\mathrm{MV}^{2+} \subset \mathrm{CB}[8]$ selectivity for the trans isomer over the cis isomer upon heteroternary complexation.

In the absence of $\mathrm{MV}^{2}+\subset \mathrm{CB}[8], 2$ exhibited a typical transcis isomerization under UV (350 nm) light irradiation, showing a gradual decrease at $343 \mathrm{~nm}$ and a concomitant increase at $430 \mathrm{~nm}$, with isosbestic points at both 297 and $419 \mathrm{~nm}$ (Supplementary Fig. S4), indicating an equilibrium between the trans and cis isomers. A photo-stationary state was reached after ca. $32 \mathrm{~s}$ in water at $\mathrm{pH}=7$ at $25^{\circ} \mathrm{C}$. The decreased absorbance at 
a

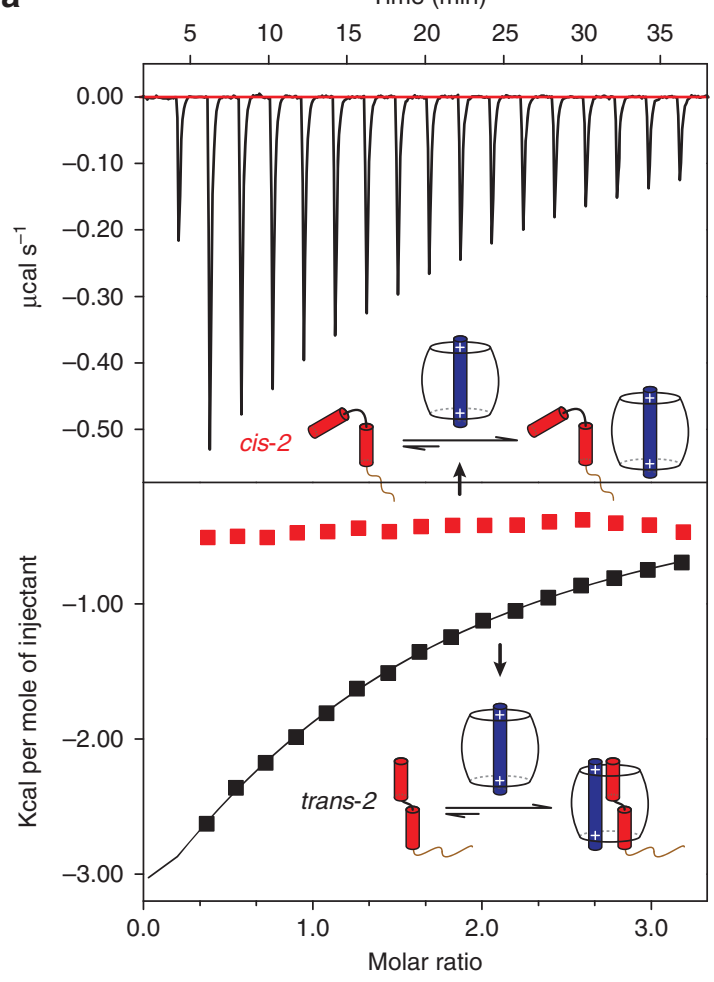

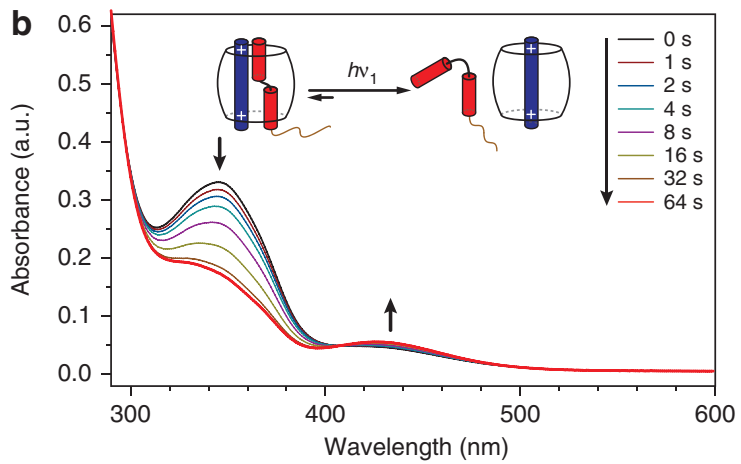
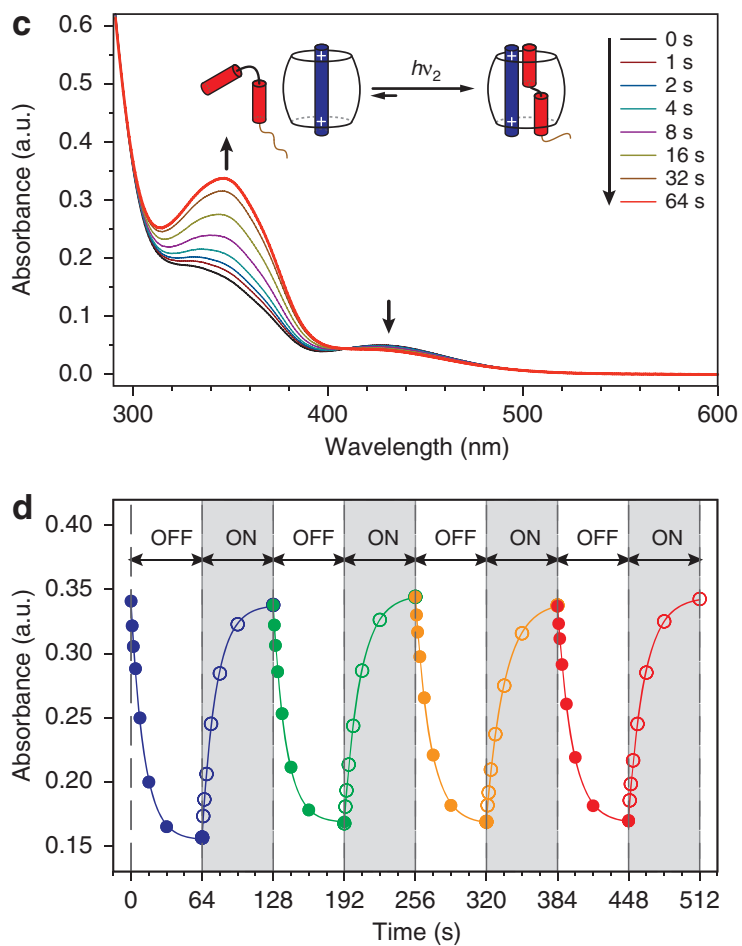

Figure 3 | Photochemical response of heteroternary complex. (a) Calorimetric titration plots of $\mathrm{MV}^{2}{ }^{+} \subset \mathrm{CB}[8]$ with cis-2 (top, in red) and trans-2 (bottom, in black) in water at $\mathrm{pH}=7$ at $25^{\circ} \mathrm{C} . \Delta G=-23.31 \mathrm{~kJ} \mathrm{~mol}^{-1}, \Delta H=-19.60 \pm 4.69 \mathrm{~kJ} \mathrm{~mol}^{-1}, \Delta \mathrm{S}=-18.79 \mathrm{~J} \mathrm{~K}{ }^{-1} \mathrm{~mol}^{-1}$. (b,c) Time-dependent UV/vis spectra of $\left(\mathrm{MV}^{2+} \mathbf{- 2}\right) \subset \mathrm{CB}[8]$ in water $(0.1 \mathrm{mM})$ under UV light $(350 \mathrm{~nm})$ irradiation for $64 \mathrm{~s}$ followed by visible light (420 nm) irradiation for $64 \mathrm{~s}$. (d) Kinetic plots of photoresponse of $\left(\mathrm{MV}^{2+} \cdot \mathbf{2}\right) \subset \mathrm{CB}[8]\left(\lambda_{\max }=346 \mathrm{~nm}\right)$ during UV and visible irradiation for four cycles.

$343 \mathrm{~nm}$ fits a first-order decay and yielded a trans-cis isomerization (confirmed by both $1 \mathrm{D}$ and $2 \mathrm{D}$ NMR spectra, Supplementary Fig. S5) rate constant of $0.296 \mathrm{~s}^{-1}$. The complementary cis-trans isomerization was achieved by visible light $(420 \mathrm{~nm})$ irradiation, with a cis-trans isomerization rate constant of $0.141 \mathrm{~s}^{-1}$

As expected, upon UV irradiation, $\left(\mathrm{MV}^{2+} \cdot 2\right) \subset \mathrm{CB}[8]$ (heteroternary complexation was confirmed by both UV/vis and NMR spectroscopy, Supplementary Fig. S6) also showed a gradual decrease at $346 \mathrm{~nm}$ and a slight increase at $425 \mathrm{~nm}$ (Fig. 3b), with an isosbestic point at $411 \mathrm{~nm}$, indicating that the heteroternary complex is indeed photoresponsive. The reverse process was readily achieved by visible light irradiation (Fig. 3c), and many cycles of alternating UV/visible irradiation could be carried out without any obvious decay (Fig. 3d). The apparent isomerization rate constant of 2 in the presence of $\mathrm{MV}^{2+} \subset \mathrm{CB}$ [8] was measured to be $0.080 \mathrm{~s}^{-1}$, which is 3.7 times slower than that of the trans-cis isomerization of $\mathbf{2}$ in the absence of $\mathrm{MV}^{2+} \subset \mathrm{CB}[8]$. This decreased rate constant suggests that heteroternary complexation has a profound effect on the trans to cis isomerization of 2. As neither $\mathrm{MV}^{2+}$ or $\mathrm{MV}^{2+} \subset \mathrm{CB}[8]$ absorbs light above $325 \mathrm{~nm}$ (Supplementary Fig. S7), the overall isomerization rate of trans-2 likely depends on the equilibrium between 'free' and 'bound' 2 in the heteroternary complex. As the $k_{\text {out }}$ for $\mathbf{2}$ is 4 orders of magnitude slower than $k_{\text {in }}$ (as measured by ITC in the form of a binding constant), it is therefore reasonable to suggest that trans- 2 undergoes isomerization almost immediately after leaving the $\mathrm{CB}[8]$ cavity, thereby 'locking' itself out of the CB[8] cavity. Subsequently, upon $420 \mathrm{~nm}$ irradiation of the solution, cis to trans isomerization of 2 led to reformation of the heteroternary complex. Together with the binding affinity studies shown in Fig. 3a, the photoirradiation generated a fully reversible transition between an original 'closed' heteroternary complex and a dissociated 'open' state of $\mathrm{MV}^{2+} \subset \mathrm{CB}[8]$ and cis-2.

Electrochemical switching upon redox-driven dimerization. Methyl viologen exhibits two consecutive one-electron reductions, and was used as the first guest in forming the heteroternary 
complex on account of its remarkable electrochemical responsiveness. The redox chemistry of viologen in the presence of $\mathrm{CB}[8]$ without $^{45}$ or with ${ }^{46}$ a second guest has been well characterized. As the transition from $\mathrm{MV}^{2+}$ to $\mathrm{MV}^{+} \cdot$ (Fig. 1a left) drives the formation of the $2: 1$ homoternary complex $\left(\mathrm{MV}^{+} \cdot\right)_{2} \subset \mathrm{CB}[8]$ (Fig. 1b left), only the first one-electron reduction of $\mathrm{MV}^{2}+$ was carried out for the demonstration of the electrochemical response of the heteroternary complex. As shown in Fig. 4ai-ii, the positive shift of $\sim 117 \mathrm{mV}$ observed in the halfwave potential $\left(\Delta E_{p}^{1}\right)$ of the first one-electron reduction of $\mathrm{MV}^{2+}$ in the presence of $\mathrm{CB}[8]$ is on account of the formation of the homoternary complex $\left(\mathrm{MV}^{+}{ }^{\bullet}\right)_{2} \subset \mathrm{CB}[8]^{45}$. Heteroternary complexation upon addition of second guest $\mathbf{2}$ induced a smaller positive shift of $E_{p}^{1} \sim 87 \mathrm{mV}$ as compared with that of $\mathrm{MV}^{2}+\subset \mathrm{CB}[8]$ (Fig. 4ai-iii), showing that the heteroternary complex is indeed electrochemically active.

Upon electrochemical reduction at $-0.7 \mathrm{~V}$, the formation of $\left(\mathrm{MV}^{+} \cdot\right)_{2} \subset \mathrm{CB}[8]$ was observed by the characteristic absorbance bands centred at 366,544 and $860 \mathrm{~nm}$ (Fig. 4b) ${ }^{45}$, confirming the dissociation of $\left(\mathrm{MV}^{2+} \cdot 2\right) \subset \mathrm{CB}[8]$. The electrochemical reoxidation of the resulting $\left(\mathrm{MV}^{+}{ }^{\bullet}\right)_{2} \subset \mathrm{CB}[8]$ complex in the presence of 2 regenerated the original heteroternary complex $\left(\mathrm{MV}^{2+} \cdot 2\right) \subset \mathrm{CB}[8]$, as the characteristic absorbance of $\left(\mathrm{MV}^{+} \cdot\right)_{2} \subset \mathrm{CB}[8]$ completely disappeared and the original absorbance of the heteroternary complex fully recovered (Supplementary Fig. S8). The combined CV and spectroelectrochemical experiments confirmed the redox-driven fully reversible transition between a 'closed' heteroternary complex and a 'closed' homoternary complex with 'unbound' second guest 2 .

In an effort to demonstrate that the external stimuli described above are able to act orthogonally in a single supramolecular system, the electrochemical response of the heteroternary complex was investigated under photoirradiation conditions. When $\left(\mathrm{MV}^{2+} \bullet\right.$ trans-2) $\subset \mathrm{CB}[8]$ was irradiated with UV light $(350 \mathrm{~nm})$, a new reduction potential was observed on account of the formation of the dissociation of heteroternary complex. Subsequent visible light $(420 \mathrm{~nm})$ irradiation promoted full recovery of the heteroternary complex as an almost identical $E_{\mathrm{pc}}$ was observed again in its native peak position, corresponding to that of the original heteroternary complex (Supplementary Fig. S9). A same similar shift trend of the $E_{\mathrm{pa}}$ during photoisomerization was also observed, first shifting to that of $\left(\mathrm{MV}^{+}{ }^{\bullet}\right)_{2} \subset \mathrm{CB}[8]$ upon UV irradiation followed by moving back to the original potential (Supplementary Fig. S9 for scan rate effect on the absolute value of shift). This reversible behaviour clearly indicated that photoirradiation was fully compatible with the redox-responsive nature of $\mathrm{MV}^{2+} \subset \mathrm{CB}[8]$ complexes, and thus offers an orthogonal handle over the supramolecular system.

Orthogonal switching on surfaces. To demonstrate how this unique orthogonally controlled system can be exploited to amplify different external stimuli, such as light and redox potential into macroscopic properties, the tuning of surface wettability was investigated. To complement previous work, in which a viologen functionalized thiol was used to form a selfassembled monolayer (SAM) on a Au substrate ${ }^{43,47}$, a SAM of thiol-containing azobenzene derivative 3 on a Au substrate was prepared by micro contact printing to offer additional characterization of surface wettability (Supplementary Fig. S10 for the photo-switchability of 3). After a 3-terminated $\mathrm{Au}$ substrate was introduced into a solution of preformed $\left(\mathrm{MV}^{2+} \mathrm{F}\right) \subset \mathrm{CB}[8]$ complex, a 2D fluorescent pattern (Fig. 5b middle: $(1,1)$ state) was readily visualized on account of the formation of the heteroternary complex $\left(\mathrm{MV}^{2+} \mathrm{F} \cdot 3\right) \subset \mathrm{CB}[8]$. A $25^{\circ}$ decrease in the water contact angle from $\theta=93^{\circ}$ (Supplementary Fig. S11) to $\theta=68^{\circ}$ (Fig. 5c middle $(1,1)$ ) occurs on account of the presence of positive charges from $\mathrm{MV}^{2+} \mathrm{F}$.

UV light (350 $\mathrm{nm}, 1 \mathrm{~min})$ irradiation of the resulting substrate in the presence of $\left(\mathrm{MV}^{2+} \mathrm{F}\right) \subset \mathrm{CB}[8]$ led to the disappearance of the fluorescent array (Fig. 5b right: $(0,0))$ and the hydrophobicity of the resulting surface recovered $\left(\theta=90^{\circ}\right.$, Fig. $5 \mathrm{c}$ right). This was apparently driven by the photoisomerization of azobenzene $\left(1 \rightarrow 0\right.$ transition), resulting in the dissociation of $\left(\mathrm{MV}^{2+} \mathrm{F} \cdot 3\right)$ $\subset \mathrm{CB}[8]$-terminated substrate into a cis-3-terminated substrate 0 state, and released $\left(\mathrm{MV}^{2+} \mathrm{F}\right) \subset \mathrm{CB}[8]$ complex (represented by 0 on account of its absence on surface). The fluorescent pattern could be rewritten onto the surface $((0,0) \rightarrow(1,1)$ transition) with a concomitant increase in the surface hydrophilicity $\left(\theta=68^{\circ}\right)$ after irradiating the resulting cis-3terminated substrate with visible light $(420 \mathrm{~nm}, 2 \mathrm{~min})$ in the same $\mathrm{MV}^{2}{ }^{+} \mathrm{F} \subset \mathrm{CB}[8]$ solution. It should be pointed out that the cis-3-terminated substrate was obtained in the presence of $\mathrm{MV}^{2+} \mathrm{F} \subset \mathrm{CB}[8]$ as a fully 'closed' state 0 in terms of recognizing other first-guest $\subset \mathrm{CB}[8]$ complex unless the cistrans photoisomerization $0 \rightarrow 1$ was carried out.

A control experiment demonstrated that a $\mathrm{Au}$ surface covered with a SAM of $\mathbf{3}$ exhibited no detectable change in surface wettability upon photoisomerization in the absence of
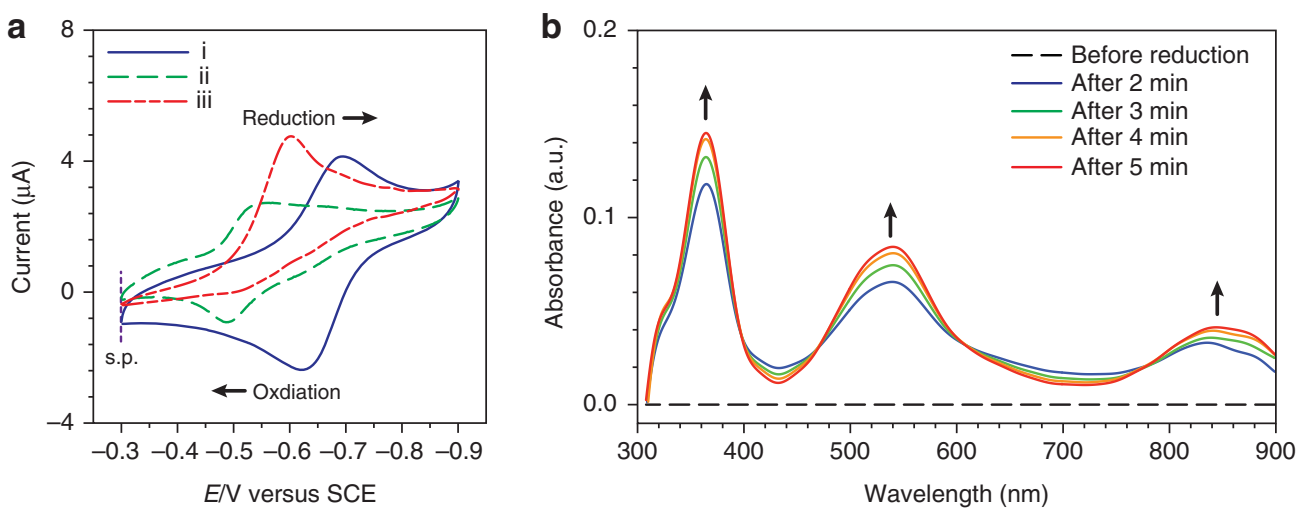

Figure 4 | Electrochemical response of the heteroternary complex. (a) Cyclic voltammograms of (i) $\mathrm{MV}^{2+}$, (ii) binary complex $\mathrm{MV}^{2+} \subset \mathrm{CB}[8]$ and (iii) heteroternary complex $\left(\mathrm{MV}^{2+} \cdot \mathbf{2}\right) \subset \mathrm{CB}[8]$ (scan rate $0.025 \mathrm{Vs}^{-1}$ ). Each sample was run at $0.25 \mathrm{mM}$ in $0.1 \mathrm{M}$ phosphate buffer at pH $=7$; a glassy carbon electrode was used as the working electrode and SCE as the reference electrode (scans start from $-0.3 \mathrm{~V}$ as indicated by the vertical dashed line in purple, to $-0.9 \mathrm{~V})$. (b) UV/vis spectra of $\left(\mathrm{MV}^{2}+\mathbf{\cdot}\right) \subset \mathrm{CB}[8]$ under electrochemical reduction $(0.1 \mathrm{mM}$ in $0.25 \mathrm{M}$ phosphate buffer at pH=7) using an indium tin oxide glass electrode as the working electrode (applied potential, $-0.7 \mathrm{~V}$ versus SCE). SCE, saturated calomel electrode. 


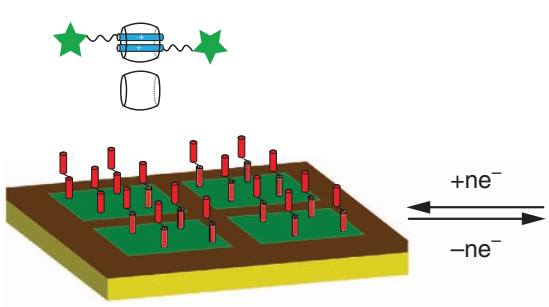

$(0,1)$

$(1,1)$

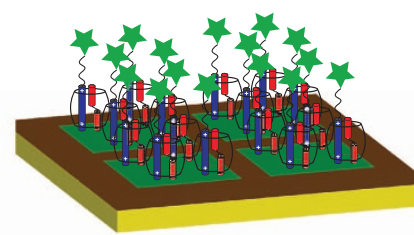

C

b
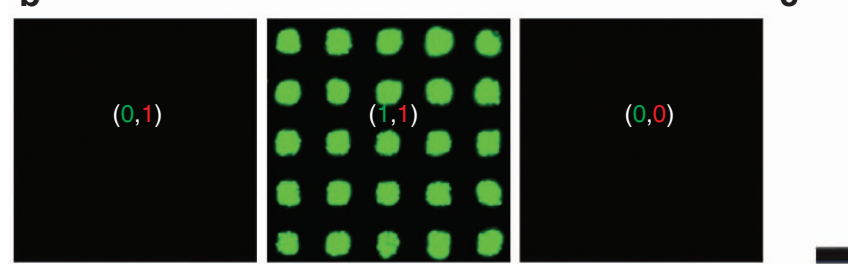

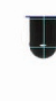

$(0,1)$

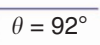

$\theta=92^{\circ}$

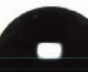

$(0,0)$
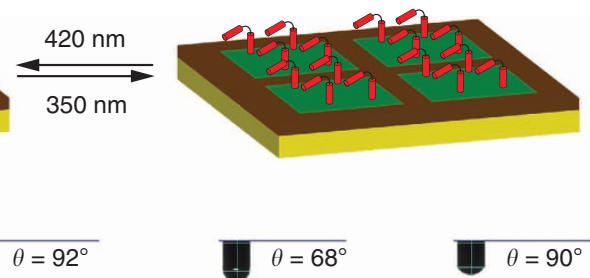

$\theta=90^{\circ}$

$(1,1)$

$(0,0)$

Figure 5 | Orthogonal switching of the heteroternary complexes on a surface. (a) Schematic illustration of isomerization-driven photoswitching $(1,1) \leftrightarrow(0,0)$ and dimerization-driven electrochemical switching $(1,1) \leftrightarrow(0,1)$. Micro-patterned fluorescent arrays were prepared by the addition of $\mathrm{MV}^{2}+\mathrm{F} \subset \mathrm{CB}[8](5 \mu \mathrm{M})$ to the 3 -terminated Au substrate for $5 \mathrm{~min}$. For photoswitching, the resulting substrate was irradiated by UV light (350 nm) for $1 \mathrm{~min}$ in the presence of $\mathrm{MV}^{2}+\mathrm{F} \subset \mathrm{CB}[8]$ followed by visible light irradiation ( $420 \mathrm{~nm}, 2 \mathrm{~min}$ ). For redox switching, the substrate was used as the working electrode for the electrochemical reduction (applied potential: $-0.7 \mathrm{~V}$ versus $\mathrm{SCE}$ ) in the presence of $0.1 \mathrm{mM} \mathrm{MV} \mathrm{MV}^{2+} \mathrm{F} \subset \mathrm{CB}[8]$ in $0.1 \mathrm{M}$ phosphate buffer $(\mathrm{pH}=7)$ for $5 \mathrm{~min}$ followed by electrochemical reoxidation $\left(-0.3 \mathrm{~V}\right.$ versus SCE) for $10 \mathrm{~min}$. (b) Fluorescence microscopy images $\left(\lambda_{\text {ex }}=488 \mathrm{~nm}\right)$ of (left): $(0,1)$ after electrochemical reduction; (middle): $(1,1)$ state with 50 (square dimension) $\times 50$ (interval length) $\mu \mathrm{m}$ arrays (as prepared, after visible light irradiation, and after electrochemical oxdiation); (right): $(0,0)$ state after UV light irradiation. (c) Water contact angle measurement of the corresponding states.

$\mathrm{MV}^{2+} \subset \mathrm{CB}[8]$ (Supplementary Fig. S11), confirming that the light-switchable surface wettability was indeed caused from the reversible dissociation/reformation of the heteroternary complex. This reversible light-induced switch of fluorescence and nonfluorescence, as well as the oscillation in surface wettability (Supplementary Fig. S12), could be repeated for at least three cycles without any obvious decay. In addition, the 'on' and 'off photoswitching $(1,1) \leftrightarrow(0,0)$ represents a writing-erasing mechanism required for data storage in a memory device.

In parallel, the redox-controlled dissociation and reformation of $\left(\mathrm{MV}^{2+} \mathrm{F} \bullet\right.$ trans-3 $) \subset \mathrm{CB}[8]$ on the surface was also investigated. Using the heteroternary complex terminated substrate as the working electrode with $\mathrm{MV}^{2+} \mathrm{F} \subset \mathrm{CB}[8]$ $(0.1 \mathrm{mM})$ in a phosphate buffer $(0.1 \mathrm{M} \mathrm{pH}=7)$ as the supporting electrolyte, the fluorescent pattern was completely removed when a potential $(-0.7 \mathrm{~V}$ versus $\mathrm{SCE})$ was applied (Fig. $5 b,(1,1) \rightarrow(0,1))$, and the hydrophobicity of the Au surface recovered $\left(\theta=92^{\circ}\right)$. It is believed that the homoternary complexation of $\left(\mathrm{MV}^{+} \cdot \mathrm{F}\right)_{2} \subset \mathrm{CB}[8]$ drives the fluorescent viologen derivative away from the trans-3-terminated substrate, resulting in a $(0,1)$ state. In contrast to the cis-3-terminated substrate resulting from UV photoirradiation, the trans-3terminated substrate is still capable of binding other firstguest $\subset \mathrm{CB}[8]$ complexes, thus distinguishing the electrochemical switch $(1,1) \rightarrow(0,1)$ from the photochemical one $(1,1) \rightarrow(0,0)$. The subsequent reoxidation (applied potential: $-0.3 \mathrm{~V}$ versus SCE) brought back both the fluorescent pattern and the hydrophilicity of the $\mathrm{Au}$ surface $\left(\theta=68^{\circ}\right)$ upon reformation of $\left(\mathrm{MV}^{2}+\mathrm{F} \bullet\right.$ trans-3) $\subset \mathrm{CB}[8]$ on a surface. This particular 'on' and 'off electrochemical switching $(1,1) \leftrightarrow(0,1)$ represents an orthogonal writing-erasing mechanism to that of the photo-switch and can be potentially employed simultaneously to greatly increase the complex structure (message) written on a surface. As both the photochemical and the electrochemical processes are fully reversible, the order of the external inputs only displays different outcomes but does not limit the direction of switching represented in Fig. 5a.

Complementarily, we also formed the heteroternary complex on a surface by first immobilizing a viologen ligand (5) on the $\mathrm{Au}$ surface followed by a sequential addition of $\mathrm{CB}[8]$ and dyelabelled azobenzene second guest 4 (Supplementary Fig. S13) 43,47 . The orthogonal switching of the heteroternary complex on the surface was confirmed by the disappearance and reappearance of linear fluorescent patterns, however, this approach sacrifices the modulation of surface wettability and hence serves as a complementary experiment.

\section{Discussion}

By incorporating both redox- and light-responsive components into a single addressable supramolecular entity, a $\mathrm{CB}[8]$-mediated host-guest complex has been shown to respond orthogonally to distinctly different stimuli through light-driven isomerization and redox-driven dimerization. Fully controlled switches between a 'closed' (1:1:1) heteroternary complex, a 'closed' (2:1) homoternary complex and a dissociated 'open' state have been demonstrated, which have the potential to be exploited in logic functions. Moreover, by designing a patterned substrate, orthogonal stimuli were amplified to tune surface properties that were readily visualized. The single $\mathrm{CB}[8]$ heteroternary complex thus offers a versatile platform for the next generation of chemical and biological devices with higher complexity.

\section{Methods}

Materials. All starting materials were purchased from Sigma Aldrich and used as received unless stated otherwise. $\mathrm{CB}[8], \mathrm{MV}^{2+}, \mathrm{N}-\left(10\right.$-mercaptodecyl) $-N^{-}$methyl-4,4'-bipyridinium chloride (5) were prepared as documented previously ${ }^{47}$.

Synthesis of 1. A solution of $\mathrm{KOH}(25 \mathrm{~g}, 380 \mathrm{mmol})$ and $p$-nitrophenol $(5 \mathrm{~g}$, $36 \mathrm{mmol})$ in water $(6 \mathrm{ml})$ was heated at $120^{\circ} \mathrm{C}$ for $1 \mathrm{~h}$ and then at $195-200^{\circ} \mathrm{C}$ for $2 \mathrm{~h}$ (ref. 48). The mixture was cooled to room temperature and dissolved in water. 
The dark-red solution was acidified to $\mathrm{pH}=3$ with concentrated $\mathrm{HCl}$, extracted with $\mathrm{Et}_{2} \mathrm{O}$ and dried over $\mathrm{Na}_{2} \mathrm{SO}_{4}$. The filtered residue was recrystallized from $\mathrm{EtOH} /$ water $(4: 1, \mathrm{v} / \mathrm{v})$ to give yellow crystals of $1(2.3 \mathrm{~g}, 59.6 \%) .{ }^{1} \mathrm{H}$ NMR $\left(400 \mathrm{MHz}, \mathrm{d}_{6}-\mathrm{DMSO}\right): \delta(\mathrm{ppm})=10.09(\mathrm{~s}, 2 \mathrm{H}), 7.72-7.70(\mathrm{~d}, 4 \mathrm{H}), 6.94-6.92$ (d, 4H). ${ }^{13} \mathrm{C}$ NMR (126 MHz, $\mathrm{d}_{6}$-DMSO): $\delta(\mathrm{ppm})=160.8,146.1,125.0,116.6$. ESI-MS $(m / z)$ : calcd. for $\mathrm{C}_{12} \mathrm{H}_{10} \mathrm{~N}_{2} \mathrm{O}_{2},[\mathrm{M}+\mathrm{H}]^{+}, 215.23$; found: 215.25 .

Synthesis of 2. A solution of 2-[2-(2-chloroethoxy) ethoxy] ethanol (1.855 g, $11.00 \mathrm{mmol})$ in EtOH $(5 \mathrm{ml})$ was added to an EtOH solution $(30 \mathrm{ml})$ of $\mathrm{KOH}$ $(561 \mathrm{mg}, 10.00 \mathrm{mmol})$ and 4-phenylazophenol $(1.982 \mathrm{~g}, 10 \mathrm{mmol})$ along with a catalytic amount of $\mathrm{KI}^{49}$. The mixture was refluxed for $16 \mathrm{~h}$, cooled to room temperature and neutralized. The filtered residue was dissolved in $\mathrm{CHCl}_{3}$, washed with water and dried over $\mathrm{MgSO}_{4}$. The filtered residue was purified by chromatography (EtOAc/hexane (1:4)) and recrystallized from $\mathrm{MeOH}$ to give 2 (1.652 g, 50.0\%). ${ }^{1} \mathrm{H}$ NMR (500 MHz, $\left.\mathrm{d}_{6}-\mathrm{DMSO}\right): \delta(\mathrm{ppm})=7.90-7.88(\mathrm{~d}, 2 \mathrm{H}, \mathrm{ar})$, 7.85-7.84 (d, $2 \mathrm{H}$, ar), 7.59-7.56 (m, 2H, ar), 7.54-7.51 (m, 1H, ar), 7.16-7.14 (m, $2 \mathrm{H}, \mathrm{ar}), 4.59-4.56(\mathrm{~d}, 2 \mathrm{H}), 4.23-4.21(\mathrm{~d}, 2 \mathrm{H}), 3.80-3.78(\mathrm{~d}, 2 \mathrm{H}), 3.69-3.65$ (d, $2 \mathrm{H}), 3.62-3.60$ (d, $2 \mathrm{H}), 3.50-3.48$ (d, $2 \mathrm{H}) .{ }^{13} \mathrm{C}$ NMR (126 MHz, $\mathrm{d}_{6}$-DMSO): $\delta(\mathrm{ppm})=161.3,152.0,146.2,130.8,129.4,124.6,122.3,115.1,70.5,70.0,69.8$, 68.8, 67.7, 60.2. ESI-MS $(m / z)$ : calculated for $\mathrm{C}_{18} \mathrm{H}_{22} \mathrm{~N}_{2} \mathrm{O}_{4},[\mathrm{M}+\mathrm{H}]^{+}, 331.34$; found: 331.39

Synthesis of 3. To a DMF solution $(25 \mathrm{ml})$ of 4-(phenyldiazenyl)phenol $(2.100 \mathrm{~g}$, $10.59 \mathrm{mmol})$ and potassium $t$-butoxide $(1.249 \mathrm{~g}, 11.13 \mathrm{mmol})$, 11-bromo-1-undecene $(2.44 \mathrm{ml}, 11.13 \mathrm{mmol})$ was added ${ }^{50}$. The mixture was refluxed for $10 \mathrm{~min}$, cooled to room temperature, poured into water $(100 \mathrm{ml})$ and extracted with hexane $(4 \times 50 \mathrm{ml})$. The organic phase was dried over $\mathrm{Mg}_{2} \mathrm{SO}_{4}$ and the filtered residue was purified by chromatography (EtOAc:hexane, 1:20) to give $\mathbf{3 a}(2.389 \mathrm{~g}$, $64.4 \%)$.

A toluene $(20 \mathrm{ml})$ solution of $3 \mathbf{a}(1 \mathrm{~g}, 2.85 \mathrm{mmol})$, AIBN $(141 \mathrm{mg}, 0.86 \mathrm{mmol})$ and thioacetic acid $(873 \mathrm{mg}, 11.47 \mathrm{mmol})$ was refluxed for $1 \mathrm{~h}$, cooled to room temperature, poured into saturated $\mathrm{NaHCO}_{3}(100 \mathrm{ml})$ and toluene $(50 \mathrm{ml})$ solution. The organic phase was washed with water $(4 \times 5 \mathrm{ml})$ and dried over $\mathrm{Mg}_{2} \mathrm{SO}_{4}$. The filtered residue was purified by chromatography (EtOAc:hexane, 1:15) to give $\mathbf{3 b}(205 \mathrm{mg}, 16.8 \%)$

A mixed $\mathrm{MeOH}(4 \mathrm{ml})$ and $1 \mathrm{M} \mathrm{HCl}$ in $\mathrm{MeOH}(1 \mathrm{ml})$ solution of $\mathbf{3 b}$ was refluxed for $5 \mathrm{~h}$, cooled to room temperature and dried to give quantitative $3 .{ }^{1} \mathrm{H}$ NMR $\left(500 \mathrm{MHz}, \mathrm{CDCl}_{3}\right): \delta(\mathrm{ppm})=7.92-7.90(\mathrm{~d}, 2 \mathrm{H}), 7.88-7.87(\mathrm{~d}, 2 \mathrm{H}), 7.51-7.48$ (m, 2H), 7.45-7.42 (m, 1H), 7.01-6.99 (m, 2H), 4.05-4.03 (t, $2 \mathrm{H}), 2.88-2.85$ $(\mathrm{t}, 2 \mathrm{H}), 2.32\left(\mathrm{~s}, 3 \mathrm{H}, \mathrm{CH}_{3}\right), 1.85-1.79(\mathrm{~m}, 2 \mathrm{H}), 1.59-1.54(\mathrm{~m}, 2 \mathrm{H}), 1.51-1.45$ $(\mathrm{m}, 2 \mathrm{H}), 1.37-1.29(\mathrm{~m}, 12 \mathrm{H}),{ }^{13} \mathrm{C} \mathrm{NMR}\left(126 \mathrm{MHz}, \mathrm{CDCl}_{3}\right): \delta(\mathrm{ppm})=161.88$, $152.92,146.98,130.44,129.17,124.91,122.67,114.85,68.51,30.80,29.65,29.62$, $29.59,29.50,29.33,29.30,29.25,28.96,26.15$.

Synthesis of 4. A MeCN solution ( $100 \mathrm{ml})$ of 4-(phenyldiazenyl)phenol $(2.10 \mathrm{~g}$, $10.59 \mathrm{mmol})$, 2-bromoethanamine hydrochloride $(1.90 \mathrm{~g}, 11.84 \mathrm{mmol})$, potassium carbonate $(3.51 \mathrm{~g}, 25.40 \mathrm{mmol})$ along with a catalytic amount of 18-crown-6 was refluxed for $36 \mathrm{~h}$, cooled to room temperature, and extracted into DCM $(2 \times 100 \mathrm{ml})$ and $1 \mathrm{M} \mathrm{HCl}(100 \mathrm{ml})$. The organic extracts were washed with water and brine, dried over $\mathrm{MgSO}_{4}$. The filtered residue was purified by chromatography (EtOAc/petroleum ether (40:60), 5:95) to a give $4 \mathrm{a}(1.56 \mathrm{~g}, 61 \%) .{ }^{1} \mathrm{H}$ NMR (400 $\left.\mathrm{MHz}, \mathrm{CDCl}_{3}\right): \delta(\mathrm{ppm})=7.99-7.97(\mathrm{~d}, 2 \mathrm{H}, \mathrm{ar}), 7.86-7.84$ (d, 2H, ar), 7.56-7.53 (m, 2H, ar), 7.51-7.49 (m, 1H, ar), 7.16-7.14 (m, 2H, ar), 4.27-4.24 (t, $\left.2 \mathrm{H}, \mathrm{CH}_{2}\right)$, $3.42-3.39\left(\mathrm{t}, 2 \mathrm{H}, \mathrm{CH}_{2}\right) .{ }^{13} \mathrm{C}$ NMR $\left(126 \mathrm{MHz}, \mathrm{CDCl}_{3}\right): \delta(\mathrm{ppm})=161.1,152.9$, 144.6, 130.3, 129.2, 123.6, 123.4, 114.6, 71.3, 41.4.

An aqueous solution $(10 \mathrm{ml})$ of $\mathbf{4 a}(27.6 \mathrm{mg}, 0.10 \mathrm{mmol})$ and FITC $(390 \mathrm{mg}$, $1 \mathrm{mmol}$ ) was stirred at room temperature for 3 days. The crude product was purified on a Varian 940-LC with a linear gradient of 5-95\% B in $30 \mathrm{~min}$ with the maximum absorbance at $363 \mathrm{~nm}$. The mobile phases were $\mathrm{H}_{2} \mathrm{O}$ (eluent $\mathrm{A}$ ) and MeCN (eluent B), respectively.

Synthesis of $\mathbf{M V}^{\mathbf{2}}+\mathbf{F}$. N-methyl-4,4'-bipyridinium iodide ${ }^{47}(2 \mathrm{~g}, 6.70 \mathrm{mmol})$ and 2-bromoethanamine hydrochloride $(1.300 \mathrm{~g}, 8.10 \mathrm{mmol})$ were refluxed in $\mathrm{MeCN}$ for 3 days. The precipitant was filtered and washed with $\mathrm{MeCN}$ and dried under vacuum. ${ }^{1} \mathrm{H}$ NMR $\left(400 \mathrm{MHz}, \mathrm{d}_{7}-\mathrm{DMF}\right): \delta(\mathrm{ppm})=9.62-9.60$ (d, 2H, ar), 9.55-9.53 (d, $2 \mathrm{H}$, ar), 9.02-9.01 (d, 2H, ar), 8.97-8.96 (d, 2H, ar), 5.13-5.16 (t, 2H, $\mathrm{CH}_{2}$ ), 4.72 (s, $\left.3 \mathrm{H}, \mathrm{CH}_{3}\right) 3.69-3.66\left(\mathrm{t}, 2 \mathrm{H}, \mathrm{CH}_{2}\right) .{ }^{13} \mathrm{C}$ NMR (126 MHz, $\left.\mathrm{d}_{6}-\mathrm{DMSO}\right): \delta(\mathrm{ppm})$ $=151.1,150.9,146.6,146.3,126.4,126.3,49.3,48.1,39.4$.

An aqueous solution $(10 \mathrm{ml})$ of the resulting compound $(45.8 \mathrm{mg}, 0.10 \mathrm{mmol})$ and FITC $(390 \mathrm{mg}, 1 \mathrm{mmol})$ was stirred at room temperature for 3 days. $\mathrm{KPF}_{6}$ $(73.6 \mathrm{mg}, 0.40 \mathrm{mmol}$ ) was added to the solution and the precipitate was filtered off and washed with water, dried under vacuum. The crude was dissolved in $5 \mathrm{ml}$ acetone, a solution of $\mathrm{n}-\mathrm{Bu}_{4} \mathrm{NCl}(11.1 \mathrm{mg}, 0.40 \mathrm{mmol})$ in $2 \mathrm{ml}$ acetone was then added, and the precipitate was filtered off and washed with water, dried under vacuum to give $\mathrm{MV}^{2}+\mathrm{F}(32.43 \mathrm{mg}, 48 \%) .{ }^{1} \mathrm{H}$ NMR $\left(\mathrm{d}_{7}-\mathrm{DMF}\right): \delta(\mathrm{ppm})=9.68-$ 9.66 (d, 2H, viologen (v)), 9.56-9.52 (d, 2H, ar, v), 9.07-9.04 (d, 2H, ar, v), 8.998.96 (d, $2 \mathrm{H}$, ar, v), 8.23-6.61 (9H, ar, Fluorescein), 5.25-5.22 (t, $\left.2 \mathrm{H}, \mathrm{CH}_{2}\right), 4.71$ $\left(\mathrm{s}, 3 \mathrm{H}, \mathrm{CH}_{3}, \mathrm{v}\right) 4.48-4.47\left(\mathrm{t}, 2 \mathrm{H}, \mathrm{CH}_{2}\right)$.
General preparation for surface experiments. For unpatterned substrates, $\mathrm{Au}$ substrates were directly immersed into $\mathrm{EtOH}$ solutions of mixed thiols (decanethiol:3, 8:1) under nitrogen atmosphere for $18 \mathrm{~h}$. For patterned substrates, PDMS stamps were wetted by EtOH solutions of decanethiol $(2 \mathrm{mM})$ and then placed onto Au substrates for $30 \mathrm{~s}$. After peeling away the stamps, the resulting substrates were washed by EtOH and immersed into solutions of mixed thiols (decanethiol:3, 8:1) in EtOH $(2 \mathrm{mM})$ under nitrogen atmosphere for $5 \mathrm{~min}$. The resulting substrates were washed by EtOH, immersed into an aqueous solution $(0.25 \mathrm{mM})$ of $\mathrm{MV}^{2+} /\left(\mathrm{MV}^{2+} \mathrm{F}\right) \subset \mathrm{CB}[8]$, and left on a shaker with 200 r.p.m. for $5 \mathrm{~min}$. The resulting substrates were washed by water and dried under nitrogen. For the complementary experiment, $\mathbf{5}$ was $\mu \mathrm{CPed}$ on a Au substrate after $\mathrm{CB}[8]$ was threaded on to a 4 -terminated Au substrate ${ }^{47}$.

Instrumentation. ${ }^{1} \mathrm{H}$ NMR (400 MHz) spectra and ${ }^{1} \mathrm{H}$ NMR (500 MHz), ${ }^{13} \mathrm{C}$ NMR, DOSY and HMQC spectra were recorded on a Bruker Avance QNP 400 and $500 \mathrm{MHz}$ Ultrashield equipped with a 5-mm BBO ATM probe with a z-gradient, respectively. ESI-MS was performed on a Fischer Thermo Scientific LTQ Velos Ion Trap Mass Spectrometer. HPLC was performed on a Varian 940LC. UV-vis spectra were recorded on a Varian Cary 4000 UV-vis spectrophotometer. Fluorescence microscopy was performed on a Leica DMI 4000B microscope. Cyclic voltammetry was carried out on a PGSTAT30 Potentiostat (EcoChemie) with a GPES electrochemical interface. The working electrode was a glassy carbon disk ( $3 \mathrm{~mm}$ diameter) and the counter electrode was a platinum wire. Spectroelectrochemistry was performed by combining a Varian Cary 4000 spectrophotometer with a PGSTAT30 Potentiostat. An ITO glass electrode was used as the working electrode. Contact angle measurements were performed on a KSV CAM 200 goniometer. Photoirradiation was performed on a LZC-ORG photoreactor with both 350 and $420 \mathrm{~nm}$ wavelength lamps. Titration experiments were carried out on a ITC200 from Microcal Inc.

\section{References}

1. Shaywitz, A. \& Greenberg, M. CREB: a stimulus-induced transcription factor activated by a diverse array of extracellular signals. Annu. Rev. Biochem. 68, 821-861 (1999).

2. Qiu, Y. \& Park, K. Environment-sensitive hydrogels for drug delivery. Adv. Drug Delivery Rev. 53, 321-339 (2001).

3. Gil, E. \& Hudson, S. Stimuli-reponsive polymers and their bioconjugates. Prog. Polym. Sci. 29, 1173-1222 (2004).

4. Barrell, M. J., Campana, A. G., von Delius, M., Geertsema, E. M. \& Leigh, D. A. Light-driven transport of a molecular walker in either direction along a molecular track. Angew. Chem. Int. Ed. 50, 285-290 (2011).

5. Saha, S. \& Stoddart, J. F. Photo-driven molecular devices. Chem. Soc. Rev. 36, 77-92 (2007).

6. Park, M. -H. et al. Chemically directed immobilization of nanoparticles onto gold substrates for orthogonal assembly using dithiocarbamate bond formation. ACS Appl. Mater. Interaces 2, 795-799 (2010).

7. Lim, C. W., Crespo-Biel, O., Stuart, M. C. A., Reinhoudt, D. N., Huskens, J. \& Ravoo, B. J. Intravesicular and intervesicular interaction by orthogonal multivalent host-guest and metal-ligand complexation. Proc. Natl Acad. Sci. USA 104, 6986-6991 (2007)

8. Ludden, M. J. W., Mulder, A., Tampe, R., Reinhoudt, D. N. \& Huskens, J. Molecular printboards as a general platform for protein immobilization: a supramolecular solution to nonspecific adsorption. Angew. Chem. Int. Ed. 46, 4104-4107 (2007).

9. Ludden, M. J. W., Peter, M., Reinhoudt, D. N. \& Huskens, J. Attachment of streptavidin to $\beta$-cyclodextrin molecular printboards via orthogonal, host-guest and protein-ligand interactions. Small 2, 1192-1202 (2006).

10. Crespo-Biel, O., Lim, C. W., Ravoo, B. J., Reinhoudt, D. N. \& Huskens, J. Expression of a supramolecular complex at a multivalent interface. J. Am. Chem. Soc. 128, 17024-17032 (2006).

11. Yagai, S. \& Kitamura, A. Recent advances in photoresponsive supramolecular self-assemblies. Chem. Soc. Rev. 37, 1520-1529 (2008).

12. Liao, X., Chen, G., Liu, X., Chen, W., Chen, F. \& Jiang, M. Photoresponsive pseudopolyrotaxane hydrogels based on competition of host-guest interactions. Angew. Chem. Int. Ed. 49, 4409-4413 (2010).

13. Nalluri, S. K. M. \& Ravoo, B. J. Light-responsive molecular recognition and adhesion of vesicles. Angew. Chem. Int. Ed. 49, 5371-5374 (2010).

14. Wang, Y., Ma, N., Wang, Z. \& Zhang, X. Photocontrolled reversible supramolecular assemblies of an azobenzene-containing surfactant with $\alpha$-cyclodextrin. Angew. Chem. Int. Ed. 46, 2823-2826 (2007).

15. Ferris, D. P., Zhao, Y. -L., Khashab, N. M., Khatib, H. A., Stoddart, J. F. \& Zink, J. I. Light-operated mechanized nanoparticles. J. Am. Chem. Soc. 131, 1686-1688 (2009).

16. Qu, D.-H., Ji, F. -Y., Wang, Q. -C. \& Tian, H. A double INHIBIT logic gate employing configuration and fluorescence changes. Adv. Mater. 18, 2035-2038 (2006). 
17. Murakami, H., Kawabuchi, A., Matsumoto, R., Ido, T. \& Nakashima, N. A multi-mode-driven molecular shuttle: photochemically and thermally reactive azobenzene rotaxanes. J. Am. Chem. Soc. 127, 15891-15899 (2005).

18. Natansohn, A. \& Rochon, P. Photoinduced motions in azo-containing polymers. Chem. Rev. 102, 4139-4175 (2002).

19. Kim, Y., Ko, Y., Jung, M., Selvapalam, N. \& Kim, K. A new photoswitchable 'on-off host-guest system. Photochem. Photobiol. Sci. 10, 1415-1419 (2011).

20. Wu, J. \& Isaacs, L. Cucurbit[7]uril complexation drives thermal trans-cisazobenzene isomerization and enables colorimetric amine detection Chem.-Eur. J. 15, 11675-11680 (2009).

21. Rauwald, U., Biedermann, F., Deroo, S., Robinson, C. V. \& Scherman, O. A. Correlating solution binding and ESI-MS stabilities by incorporating solvation effects in a confined cucurbit[8]uril system. J. Phys. Chem. B 114, 8606-8615 (2010).

22. Maddipatla, M., Kaanumalle, L. \& Natarajan, A. Preorientation of olefins toward a single photodimer: cucurbituril-mediated photodimerization of protonated azastilbenes in water. Langmuir 23, 7545-7554 (2007).

23. Lei, L., Luo, L., Wu, X.-L., Liao, G.-H., Wu, L.-Z. \& Tung, C.-H. Cucurbit[8] uril-mediated photo dimerization of alkyl 2-naphthoate in aqueous solution. Tetrahedron Lett. 49, 1502-1505 (2008).

24. Yang, C. et al. Highly stereoselective photocyclodimerization of alphacyclodextrin-appended anthracene mediated by $\gamma$-cyclodextrin and cucurbit[8] uril: a dramatic steric effect operating outside the binding site. J. Am. Chem. Soc. 130, 8574-8575 (2008).

25. Barooah, N., Pemberton, B. C. \& Sivaguru, J. Manipulating photochemical reactivity of coumarins within cucurbituril nanocavities. Org. Lett. 10, 3339-3342 (2008).

26. von Delius, M., Geertsema, E. M. \& Leigh, D. A. A synthetic small molecule that can walk down a track. Nat. Chem. 2, 96-101 (2010).

27. Klajn, R. et al. Dynamic hook-and-eye nanoparticle sponges. Nat. Chem. 1, 733-738 (2009).

28. Trabolsi, A. et al. Radically enhanced molecular recognition. Nat. Chem. 2, 42-49 (2010).

29. Rekharsky, M. V. et al. A synthetic host-guest system achieves avidin-biotin affinity by overcoming enthalpy-entropy compensation. Proc. Natl Acad. Sci. USA 104, 20737-20742 (2007).

30. Kim, H., Jeon, W., Ko, Y. \& Kim, K. Inclusion of methylviologen in cucurbit[7]uril. Proc. Natl Acad. Sci. USA 99, 5007-5011 (2002).

31. Gadde, S., Batchelor, E. K. \& Kaifer, A. E. Electrochemistry of redox active centres encapsulated by non-covalent methods. Aust. J. Chem. 63, 184-194 (2010).

32. Nepogodiev, S. \& Stoddart, J. Cyclodextrin-based catenanes and rotaxanes. Chem. Rev. 98, 1959-1976 (1998)

33. Lagona, J., Mukhopadhyay, P., Chakrabarti, S. \& Isaacs, L. The cucurbit[n]uril family. Angew. Chem. Int. Ed. 44, 4844-4870 (2005).

34. Kim, K., Selvapalam, N., Ko, Y. H., Park, K. M., Kim, D. \& Kim, J. Functionalized cucurbiturils and their applications. Chem. Soc. Rev. 36, 267-279 (2007).

35. Lee, J., Samal, S., Selvapalam, N., Kim, H. \& Kim, K. Cucurbituril homologues and derivatives: new opportunities in supramolecular chemistry. Acc. Chem. Res. 36, 621-630 (2003)

36. Marquez, C., Hudgins, R. \& Nau, W. Mechanism of host-guest complexation by cucurbituril. J. Am. Chem. Soc. 126, 5806-5816 (2004).

37. Nau, W. M., Ghale, G., Hennig, A., Bakirci, H. \& Bailey, D. M. Substrateselective supramolecular tandem assays: monitoring enzyme inhibition of arginase and diamine oxidase by fluorescent dye displacement from calixarene and cucurbituril macrocycles. J. Am. Chem. Soc. 131, 11558-11570 (2009).

38. Jeon, W. et al. Complexation of ferrocene derivatives by the cucurbit[7]uril host: a comparative study of the cucurbituril and cyclodextrin host families. J. Am. Chem. Soc. 127, 12984-12989 (2005).

39. Bush, M., Bouley, N. \& Urbach, A. Charge-mediated recognition of n-terminal tryptophan in aqueous solution by a synthetic host. J. Am. Chem. Soc. 127, 14511-14517 (2005)
40. Rauwald, U. \& Scherman, O. A. Supramolecular block copolymers with cucurbit[8]uril in water. Angew. Chem. Int. Ed. 47, 3950-3953 (2008).

41. Liu, Y., Yu, Y., Gao, J., Wang, Z. \& Zhang, X. Water-soluble supramolecular polymerization driven by multiple host-stabilized charge-transfer interactions. Angew. Chem. Int. Ed. 49, 6576-6579 (2010).

42. Hwang, I. et al. Noncovalent immobilization of proteins on a solid surface by cucurbit[7]uril-ferrocenemethylammonium pair, a potential replacement of biotin-avidin pair. J. Am. Chem. Soc. 129, 4170-4171 (2007).

43. Tian, F., Cziferszky, M., Jiao, D., Wahlstroem, K., Geng, J. \& Scherman, O. A. Peptide separation through a $\mathrm{cb}[8]$-mediated supramolecular trap-and-release process. Langmuir 27, 1387-1390 (2011).

44. Moon, K., Grindstaff, J., Sobransingh, D. \& Kaifer, A. Cucurbit[8] uril-mediated redox-controlled self-assembly of viologen-containing dendrimers. Angew. Chem. Int. Ed. 43, 5496-5499 (2004).

45. Jeon, W., Kim, H., Lee, C. \& Kim, K. Control of the stoichiometry in host-guest complexation by redox chemistry of guests: inclusion of methylviologen in cucurbit[8]uril. Chem. Commun. 38, 1828-1829 (2002)

46. Jeon, W. et al. Molecular loop lock: a redox-driven molecular machine based on a host-stabilized charge-transfer complex. Angew. Chem. Int. Ed. 44, 87-91 (2005).

47. Tian, F., Cheng, N., Nouvel, N., Geng, J. \& Scherman, O. A. Site-selective immobilization of colloids on Au substrates via a noncovalent supramolecular 'handcuff. Langmuir 26, 5323-5328 (2010).

48. Ghosh, S., Usharani, D., Paul, A., De, S., Jemmis, E. D. \& Bhattacharya, S. Design, synthesis, and DNA binding properties of photoisomerizable azobenzene-distamycin conjugates: an experimental and computational study. Bioconjugate Chem. 19, 2332-2345 (2008).

49. Allcock, H. R. \& Kim, C. Liquid crystalline phosphazenes. high polymeric and cyclic trimeric systems with aromatic azo side groups. Macromolecules 22, 2596-2602 (1989).

50. Klajn, R., Wesson, P. J., Bishop, K. J. M. \& Grzybowski, B. A. Writing selferasing images using metastable nanoparticle 'inks'. Angew. Chem. Int. Ed. 48, 7035-7039 (2009).

\section{Acknowledgements}

We thank Z. Rong and Professor U. Steiner for Au substrates and PDMS stamps, S. Jones and Dr R. Coulston for compound 3, G. Gunkel and K. Y. Tan for contact angle measurements, Dr E. Reisner and Dr M. Kato for spectroelectrochemical experiments and discussion. F.T. is grateful to the CSC Cambridge and Duke of Edinburgh Scholarships. F.B. thanks the German Academic Exchange Service (DAAD) for financial support. This work was also supported by the EPSRC (EP/F035535/1), an ERC Starting Investigator Grant (ASPiRe) and a Next Generation Fellowship provided by Walters-Kundert Foundation.

\section{Author contributions}

F.T. designed the research, performed the majority of the experiments and composed the manuscript. D.J. performed and interpreted the NMR measurements. F.B. performed and interpreted the ITC data. O.A.S. supervised the research and contributed to the preparation of the manuscript. All authors discussed the results and commented on the manuscript.

\section{Additional information}

Supplementary Information accompanies this paper at http://www.nature.com/ naturecommunications

Competing financial interests: The authors declare no competing financial interests

Reprints and permission information is available online at http://npg.nature.com/ reprintsandpermissions/

How to cite this article: Tian, F. et al. Orthogonal switching of a single supramolecular complex. Nat. Commun. 3:1207 doi: 10.1038/ncomms2198 (2012). 